University of Nebraska - Lincoln

DigitalCommons@University of Nebraska - Lincoln

3-1-2021

\title{
Breed differences in placental development during late gestation between Chinese Meishan and White crossbred gilts in response to intrauterine crowding
}

Jeremy R. Miles

USDA, ARS, U.S. Meat Animal Research Center (USMARC), jeremy.miles@usda.gov

Jeffrey L. Vallet

USDA ARS Roman L. Hruska U.S. Meat Animal Research Center

Follow this and additional works at: https://digitalcommons.unl.edu/hruskareports

Part of the Beef Science Commons, and the Meat Science Commons

Miles, Jeremy R. and Vallet, Jeffrey L., "Breed differences in placental development during late gestation between Chinese Meishan and White crossbred gilts in response to intrauterine crowding" (2021). Roman L. Hruska U.S. Meat Animal Research Center. 556.

https://digitalcommons.unl.edu/hruskareports/556

This Article is brought to you for free and open access by the U.S. Department of Agriculture: Agricultural Research Service, Lincoln, Nebraska at DigitalCommons@University of Nebraska - Lincoln. It has been accepted for inclusion in Roman L. Hruska U.S. Meat Animal Research Center by an authorized administrator of DigitalCommons@University of Nebraska - Lincoln. 


\title{
Breed differences in placental development during late gestation between Chinese Meishan and White crossbred gilts in response to intrauterine crowding
}

\author{
Jeremy R. Miles *, Jeffrey L. Vallet \\ USDA, U.S. Meat Animal Research Center, Clay Center, NE, 68933, USA ${ }^{1}$
}

\section{A R T I C L E I N F O}

\section{Keywords:}

Uterine capacity

Intrauterine crowding

Placental development

Meishan

Swine

\begin{abstract}
A B S T R A C T
The objective of this study was to evaluate placental development during late gestation (day 100) between Chinese Meishan (CM; $n=7$ ) and White crossbred (WC; $n=5$ ) gilts following intrauterine crowding induced by unilaterally hysterectomy-ovariectomy. Gross placental morphology and areolae density as well as histological morphology (i.e., folded bilayer and placental stroma) were analyzed using computer-assisted morphometry for placentas of the smallest and largest fetuses within each litter. There was a breed by fetal size interaction $(P<0.01)$ for areolae density in which placentas for large CM fetuses had greater areolae density compared to small CM fetuses, but the density of areolae was greater for CM fetuses compared to WC fetuses, irrespective of fetal size. The width of the folded bilayer was greater $(P<0.01)$ in placentas for WC gilts compared to CM gilts, irrespective of fetal size. Placentas for small fetuses had greater $(P<0.01)$ folded bilayer width compared to large fetuses, irrespective of breed. The placental stromal width was greater $(P<0.01)$ in placentas for large fetuses compared to small, irrespective of breed. The difference between stromal width in placentas between divergent-sized littermates, however, was greater $(P=0.05)$ in WC gilts compared to CM gilts, indicating there was a limited response to intrauterine crowding in CM gilts. These results indicate there is an altered placental development during late gestation in CM compared to WC gilts, thus, there are likely different mechanisms for responding to intrauterine crowding between breeds.
\end{abstract}

\section{Introduction}

In the swine industry, there has been selection for increased ovulation and litter size during the past 20 years and as a consequence

\footnotetext{
* Corresponding author.

E-mail address: jeremy.miles@usda.gov (J.R. Miles).

${ }^{1}$ Mention of trade names is necessary to report factually on available data; however, the USDA neither guarantees nor warrants the standard of the product, and the same by USDA implies no approval of the product to the exclusion of others that may also be suitable. The USDA prohibits discrimination in all its programs and activities on the basis of race, color, national origin, age, disability, and where applicable, sex, marital status, familial status, parental status, religion, sexual orientation, genetic information, political beliefs, reprisal, or because all or part of an individual's income is derived from any public assistance program. (Not all prohibited bases apply to all programs.) Persons with disabilities who require alternative means for communication of program information (Braille, large print, audiotape, etc.) should contact USDA's TARGET Center at (202) 720-2600 (voice and TDD). To file a complaint of discrimination, write to USDA, Director, Office of Civil Rights, 1400 Independence Avenue, S.W., Washington, D.C. 20250-9410, or call (800) 795-3272 (voice) or (202) 720-6382 (TDD). USDA is an equal opportunity provider and employer.
} 
there has been an increase in preweaning mortality. Increased piglet mortality has been due, in part, to greater within-litter birth weight variation and the production of smaller littermate piglets due to limitation in uterine capacity and fetal crowding (Roehe and Kalm, 2000; Mesa et al., 2006). The development of the placenta has direct implications on uterine capacity, fetal growth and survival as well as postnatal piglet growth and survival (Vallet et al., 2002, 2014). The placenta of pigs is classified as a non-invasive, epitheliochorial placenta in which primary nutrient, gas and waste transfer between the maternal and fetal tissues occurs via hemotrophic (i.e., capillary blood) exchange (Friess et al., 1980). During late gestation, increased hemotrophic exchange occurs via modification of the folded bilayer consisting of an intact uterine epithelium and trophectoderm embedded in loose stroma with there being increases in width and complexity (Leiser and Kaufmann, 1994; Vallet and Freking, 2007). In addition, histotrophic (i.e., glandular) exchange occurs via accessory placental areolae juxtaposed to uterine glandular openings (Friess et al., 1981). Histotrophic exchange occurs during later stages of gestation when there is exchange of many different glycoproteins (Friess et al., 1981; Bazer et al., 2012), particularly uteroferrin, which contributes to transfer of iron from the maternal to the fetal tissues (Roberts et al., 1986) with this being indicative of the importance of the placental areolae as gestation progresses. Adequate hemotrophic and histotrophic exchange across the placenta is essential for growth and development of the fetus and ultimately the well-being of neonatal piglets.

Differences in placental morphology during gestation have been observed for divergent-sized littermates following intrauterine crowding that occurs subsequent to unilateral hysterectomy ovariectomy and breeding of females (UHO; (Vallet and Freking, 2007)). Placental stromal width above of the folded bilayer adjacent to the largest fetuses were greater than for the smallest fetuses. In contrast, the folded bilayer width and complexity was greater in the folded bilayer tissue adjacent to the smallest fetuses compared to the largest fetuses. These morphometric differences are indicative that there is a compensatory mechanism of placentas of small fetuses in a crowded uterine environment by increasing the feto-maternal surface area in response to the overall decreased size of the placenta (Vallet and Freking, 2007). Unfortunately, at some point the placental stroma becomes limited for small littermate fetuses and the tissues of the folded bilayer are no longer modified resulting in limited growth of the small fetuses, therefore, there is an increased probability of fetal loss and greater within-litter birth weight variation (Vallet and Freking, 2007).

Chinese Meishan (CM) pigs have a larger litter size and produce piglets that weigh less than contemporary Western pig breeds (White et al., 1993; Miles et al., 2012). Despite their smaller size, CM piglets have lesser preweaning mortality rates compared to piglets of Western breeds (Legault, 1985; Lee and Haley, 1995). Hypotheses for the mechanisms for the relatively greater reproductive prolificacy of CM pigs include increased ovulation rate (Ashworth et al., 1990; Haley and Lee, 1993), greater uniformity of conceptus development (Bazer et al., 1988), increased uterine capacity (Christenson et al., 1993; Ford et al., 2002), increased placental efficiency (Wilson and Ford, 2001), increased placental vascularity (Biensen et al., 1998; Wilson et al., 1998), increased complexity of the placental folded bilayer (Hong et al., 2014), and greater physiological maturation at birth (Le Dividich et al., 1991; Herpin et al., 1993; Miles et al., 2012). It, however, is unknown how the MS pig placenta responds to intrauterine crowding in terms of gross development as well as microscopic development of the placenta for divergent-sized littermates. The objective of the current study, therefore, was to evaluate placental development during late gestation between $\mathrm{CM}$ and White crossbred gilts following intrauterine crowding induced by conducting UHO before the breeding of gilts.

\section{Materials and methods}

\subsection{Animals}

All animal protocols were approved by the US Meat Animal Research Center (USMARC) Animal Care and Use Committee and met the USDA and Federation of Animal Science Societies (FASS, 2010) guidelines for the care and use of animals. Purebred CM pigs were imported to the USMARC in 1989 and were maintained by inter se mating among eight sire lines. White crossbred (WC) pigs from a randomly selected control population of pigs consisting of a four-breed composite having equal Chester White, Landrace, Large White, and Yorkshire breed composition were maintained by inter se mating among ten sire lines (Freking et al., 2007). There were UHO surgeries conducted on similar-aged CM and WC gilts at approximately 60 days of age to induce intrauterine crowding following subsequent breeding (Christenson et al., 1987). This earlier age was a modification of the originally-conducted UHO procedure and was necessary for conducting the UHO procedure in CM gilts due to the limited vasculature of the reproductive tract prior to puberty in these gilts (unpublished observation). Briefly, gilts were sedated using acepromazine (0.3 mg/kg BW; Iowa Veterinary Supply Company, Sioux City, IA, USA) followed by induction of anesthesia using thiopental sodium (Iowa Veterinary Supply Company) with analgesia being maintained using isoflurane (Iowa Veterinary Supply Company). For UHO surgeries, one ovary and the corresponding ipsilateral uterine horn were removed from the gilts on which this procedure was conducted. This process reduces the total intrauterine space by one-half and as a consequence there is compensatory ovarian hypertrophy with ovulation rate being similar to when both ovaries are present; thereby, providing a method for creating a crowded intrauterine environment in which litter size is no longer affected by ovulation rate allowing for a direct determination of gilt uterine capacity (Christenson et al., 1987). Following recovery from UHO surgeries ( $<200$ days of age) and after having at least two estrous cycles, gilts were naturally bred using single sires of the same breed at the time of estrous detection (day 0 ) and again $24 \mathrm{~h}$ later with the same sire being used for breeding.

At day 100 of the gestational period, there was removal of the other uterine horn from pregnant gilts (seven and five CM and WC gilts, respectively) using a similar protocol as described for the UHO. Ovulation rate was recorded for each gilt. There was an incision into the uterine horn along the anti-mesometrial side of the uterus and after removal from the uterus, all fetuses were weighed to identify the smallest and largest littermate fetuses within each litter. Subsequently, a tissue section $(\sim 2 \mathrm{~cm} \times 2 \mathrm{~cm})$ consisting of intact uterine-placental interface were collected immediately adjacent but external to the amnion for the smallest and largest littermates. These tissue sections were immediately placed into cassettes and immersed in $10 \%$ buffered formalin for later histological evaluation. 
The reproductive tracts were subsequently stored at room temperature (RT) for approximately $2 \mathrm{~h}$ to ensure complete separation of placentas from the endometrium and after this 2 -h period the placenta for each fetus was completely separated and weighed. The entire placentas from the smallest and largest littermates were retained for additional gross placental morphological evaluations.

\subsection{Breed response to intrauterine crowding}

The overall breed response to intrauterine crowding was assessed for uterine capacity, fetal survival, fetal and placental weight variation, placental efficiency, and allometric growth. There was determination of uterine capacity by counting the total number of viable fetuses within each litter. There was determination of percentage fetal survival based on the proportion of live fetuses relative to number of ovulations for an individual gilt. Within-litter fetal and placental weight variation was determined using the coefficient of variation of the average fetal and placental weight within each litter. Placental efficiency was quantified based on the fetal weight to placental weight ratio (Wilson and Ford, 2001). Allometric growth was determined by evaluating the slope of the linear regression of the natural log transformed fetal weight to the natural log transformed placental weight within individual litters. An allometric slope of 1 indicates that changes in fetal weight are directly proportional to changes in placental weight; whereas an allometric slope of less than 1 indicates that fetal weight is maintained disproportionally to placental weight and indicative there was a fetal sparing effect for growth (Vallet and Freking, 2007).

\subsection{Gross placental morphology}

Intact placentas from the smallest and largest fetal littermates were submerged in distilled $\mathrm{H}_{2} \mathrm{O}$ within a volumetric beaker to determine volume displacement. The wet placentas were then placed on a glass plate and the placenta was completely spread out with the trophectoderm surface (i.e., placental surface directly facing the maternal endometrium) facing upward. The entire placenta was photographed using a D100 Nikon digital camera (Nikon Inc., Melville, NY) with a Tamron AF 28-300 mm lens (Tamron USA, Inc., Commack, NY) and photo stand using similar positioning and lighting for each placenta. These images were used to determine length, width, and surface area of the placentas. In addition, images were taken from random $5 \mathrm{~cm}^{2}$ locations $(n=3)$ on the placentas to assess areolae density across the surface of the placenta (Fig. 1). The average areolae density from the three random locations was used to estimate total areolae number based on surface area of corresponding placentas. All gross morphometric analyses were performed using the Bioquant Nova Prime (version 6.90.10) image software (Bioquant, Nashville, TN, USA).

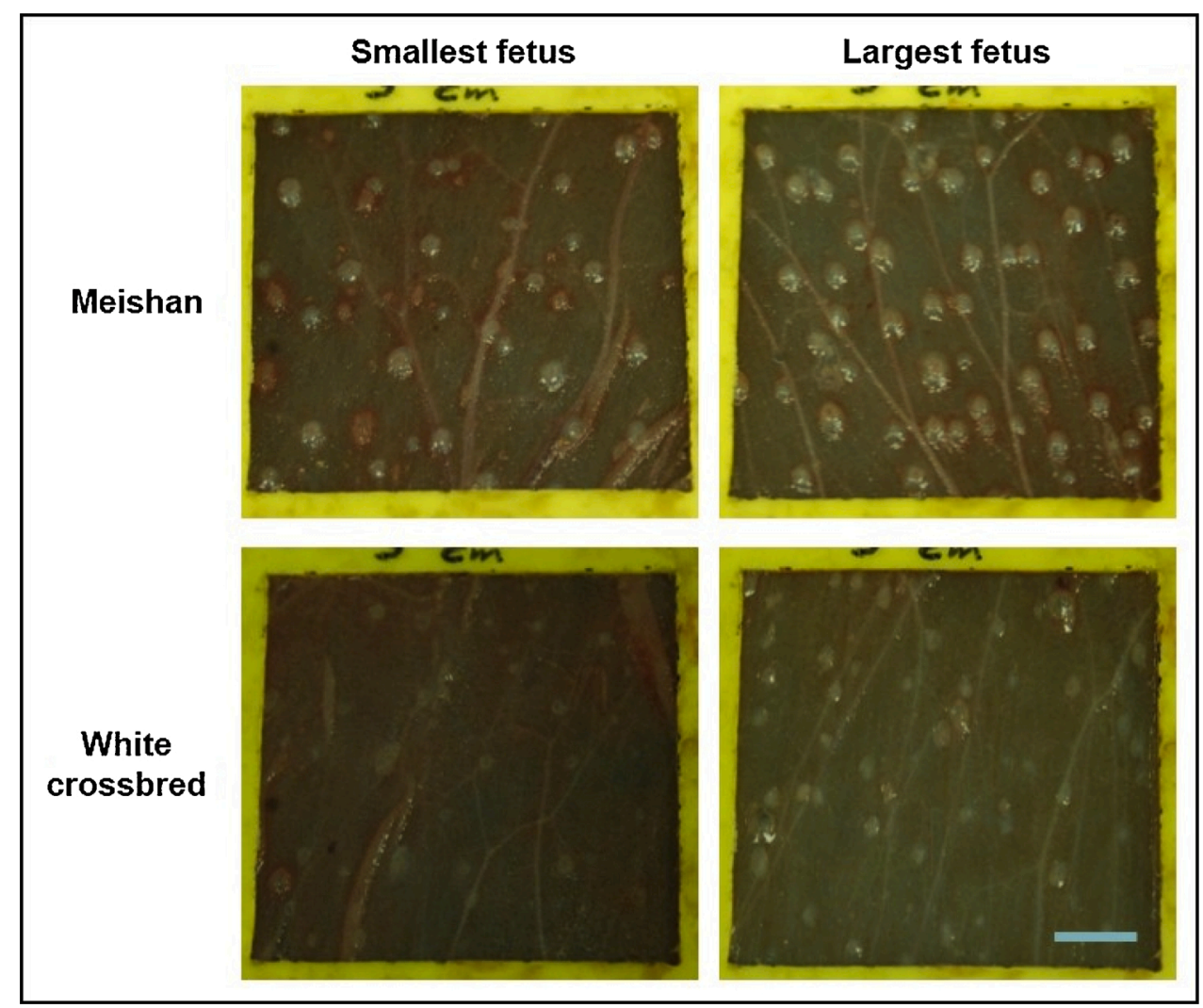

Fig. 1. Representative images of placental areolae at day 100 of the gestational period for the placentas of the smallest and largest fetal littermates when there was intrauterine crowding in Meishan or White crossbred gilts; Scale bar equals $1 \mathrm{~cm}$. 


\subsection{Histological placental morphology}

The intact uterine endometrium and placental tissues for histology were fixed in $10 \%$ buffered formalin with gentle rocking overnight at room temperature (RT). The following day tissues were washed twice in PBS for $1 \mathrm{~h}$ and using a graded series of ethanol washes ( $1 \mathrm{~h}, 25 \%$ ethanol; $1 \mathrm{~h}, 35 \%$ ethanol; 1 h, $50 \%$ ethanol; $1 \mathrm{~h} 70 \%$ ethanol) with gentle rocking at RT and stored at $4{ }^{\circ} \mathrm{C}$ until embedding in paraffin. Tissues were then washed with gentle rocking at RT through a grade series of ethanol ( $2 \mathrm{~h}$ in $95 \%$ ethanol, $2 \mathrm{~h}$ in absolute ethanol, and overnight in absolute ethanol), xylene $(2 \times 2 \mathrm{~h}$ in xylene and overnight in xylene) and paraffin ( $2 \times 2 \mathrm{~h}$ in paraffin and overnight in paraffin). Tissues were trimmed and embedded in fresh paraffin such that the uterine wall was oriented with the long axis of the uterine horn and perpendicular to the placental folds. Tissues were sectioned ( $6 \mu \mathrm{m})$, placed on coated glass slides, processed through a graded series of xylene and ethanol, stained with hematoxylin and eosin (Sigma, St. Louis, MO, USA), processed through a graded series of ethanol and xylene, and cover slips were applied with Permount (Fisher Scientific, Pittsburgh, PA, USA). Sections were imaged using a Zeiss Axioplan 2 microscope (Carl Zeiss Microscopy, LLC, White Plains, NY, USA) fitted with a chargecoupled device camera (Qioptic Imaging Solutions, Fairport, NY, USA). The images of intact uterine endometrium and placental tissues were oriented such that the placental stroma was above, the maternal endometrium was below, and the folded bilayer was centrally located between the stroma and endometrium (Fig. 2). These images were used to determine the total placental width, the folded bilayer width, and the placental stromal width using morphometric techniques previously described (Vallet and Freking, 2007). Histological morphometric analyses were performed using the Bioquant Nova Prime image software (Bioquant).

\subsection{Statistical analysis}

All data were analyzed using MIXED model procedures for ANOVA (Steel et al., 1997; SAS, 2003). When there was a significant F-statistic, there were determinations of mean differences using a Dunnett multiple comparison test (Steel et al., 1997; SAS, 2003). There were considered to be mean differences when there was a $P \leq 0.05$ and tendencies when there was a $P=0.06$ and $P=0.10$. Data for ovulation rate, uterine capacity, and fetal survival were analyzed using a model including the fixed effect of breed. Fetal weight, placental weight, within-litter fetal and placental weight variation, and placental efficiency from every fetus within a litter were analyzed using a model including the fixed effect of breed, covariate of litter size, and random effect of gilt within breed.

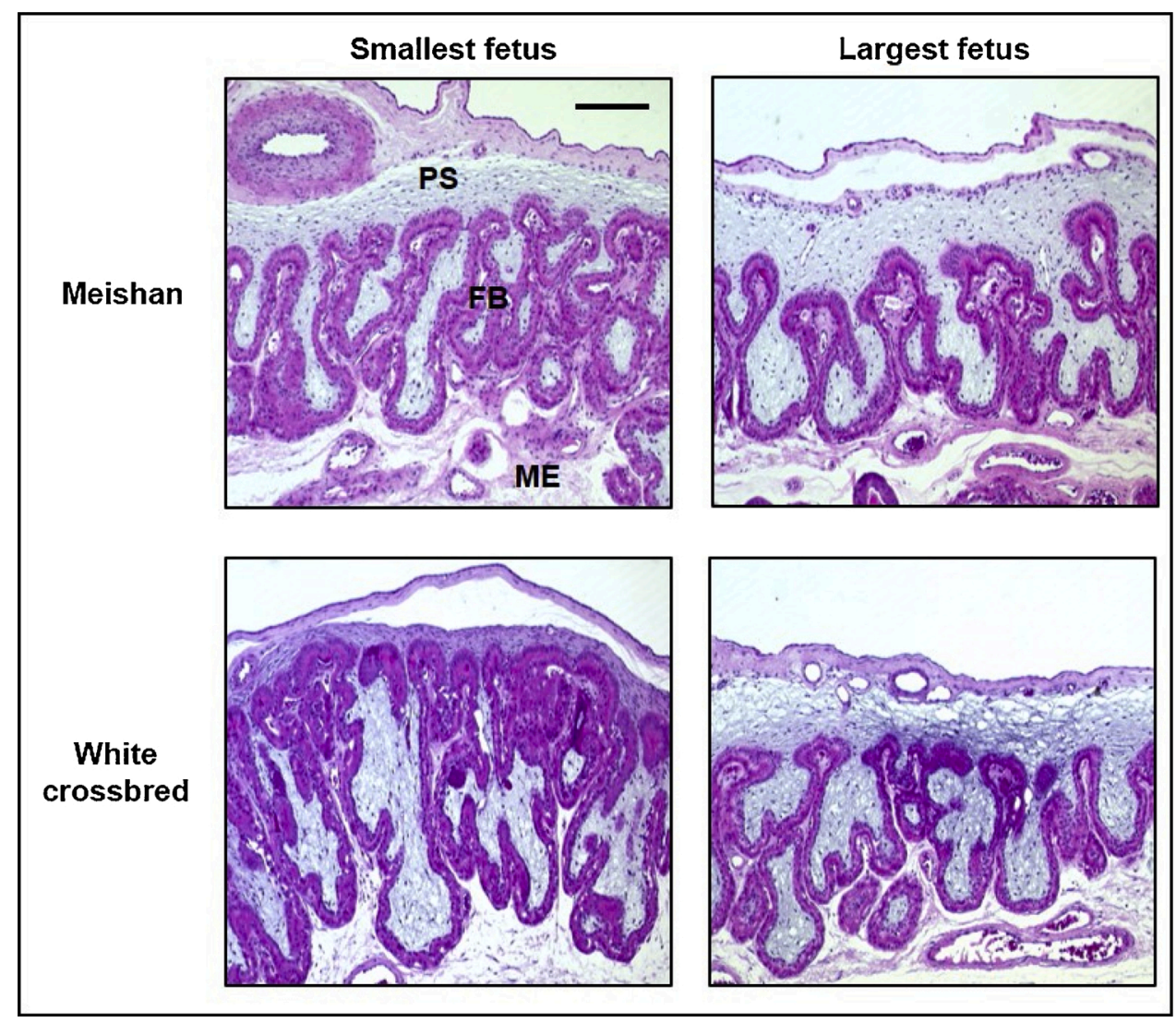

Fig. 2. Representative images of the feto-maternal interface at day 100 of gestation for the placentas of the smallest and largest fetal littermates when there was intrauterine crowding in Meishan or White crossbred gilts; PS = placental stroma; FB = folded bilayer; ME = maternal endometrium; Scale bar equals $200 \mu \mathrm{m}$. 
Allometric growth rates were assessed by determining the slope of the regression for the natural log fetal weight to the natural log placental weight and slopes for each litter were analyzed using a model including the fixed effect of breed and the covariate of litter size. Gross and histological morphological data were analyzed from the divergent-sized littermates using a model that included the fixed effects of breed, fetal size, interaction of fixed effects, covariate of litter size, and random effect of gilt within breed by fetal size interaction. In addition, data for fetal and placental weights were analyzed using a similar model as the morphological data to confirm that the UHO procedure resulted in divergent growth of the smallest and largest littermates. Data for differences in total placental, folded bilayer, and placental stromal widths among divergent-sized littermates were analyzed using a model including the fixed effect of breed, covariate of litter size, and random effect of gilt within breed.

\section{Results}

\subsection{Breed response to intrauterine crowding}

Data included in Table 1 indicate there is an overall breed response between CM and WC gilts following intrauterine crowding at day 100 of the gestational period. Ovulation rate was greater $(P=0.0286)$ in CM gilts compared to WC gilts. Uterine capacity and fetal survival, however, did not differ between CM and WC gilts (Table 1). Although fetal weight was not different between the two breeds, within-litter fetal weight variation tended $(P=0.0790)$ to be less for CM compared to WC gilts. Placental weight, within-litter placental weight variation, and placental efficiency were not different for CM and WC gilts (Table 1). In Fig. 3, there is a plot depiction of the natural log fetal weight to the natural log placental weight for individual fetuses and corresponding linear regressions for this association for CM and WC gilts. The slopes of the linear regressions correspond to the allometric growth rate within each litter and tended to be less $(P=0.0712)$ in CM compared to WC gilts (Table 1$)$.

\subsection{Gross placental morphology}

Results reported in Table 2 indicate there is an effect of breed (CM compared with WC) and fetal size (smallest compared with largest fetal littermates) for gross placental morphology at day 100 of the gestational period as a result of intrauterine crowding. As expected, as a result of UHO, both fetal and placental weight were less $(P<0.0008)$ in the smallest compared to largest littermates $(470.1 \pm 42.4 \mathrm{~g}$ compared with $778.5 \pm 42.4 \mathrm{~g}$ and $118.2 \pm 17.5 \mathrm{~g}$ compared with $217.5 \pm 17.5 \mathrm{~g}$, respectively for fetal and placental weight), irrespective of breed of dam. There were no breed or fetal size effects on placental efficiency (Table 2). The volume displacement, surface area, and length of placentas were less $(P<0.0005)$ in the smallest compared to the largest littermates $(108.3 \pm$ $15.7 \mathrm{~mL}$ and $201.0 \pm 15.7 \mathrm{~mL}, 1129.6 \pm 100.1 \mathrm{~cm}^{2}$ and $1625.3 \pm 100.1 \mathrm{~cm}^{2}$, and $43.7 \pm 2.6 \mathrm{~cm}$ and $63.3 \pm 2.6 \mathrm{~cm}$, respectively for volume displacement, surface area, and length), irrespective of breed of dam. In addition, the placental length tended $(P=0.0592)$ to be greater for placentas of CM compared to WC gilts $(57.3 \pm 2.4 \mathrm{~cm}$ vs. $49.7 \pm 2.9 \mathrm{~cm}$, respectively). There was a tendency $(P=$ 0.0591 ) for a breed by fetal size interaction in placental width (Table 2) because placentas for CM littermates were similar in width but placentas for WC gilts differed in size (i.e., smallest less compared to largest) and the largest placentas for littermate WC gilts were wider than all other placentas. There was a significant $(P=0.0097)$ breed by fetal size interaction for the areolae density. There was the greatest areolae density in placenta of large CM fetuses, and this density was less in placentas for small CM fetuses. Areolae density was less for WC fetuses compared to CM fetuses, irrespective of fetal size (Table 2). Similarly, there tended $(P=0.0855)$ to be a breed by fetal size interaction for estimated total areolae number for placentas with there being the largest number of areolae for the largest CM littermate with the placentas of the smallest CM and largest WC littermates having intermediate and the smallest WC littermates

Table 1

Overall breed response to intrauterine crowding between Meishan and White crossbred gilts at day 100 of the gestational period ${ }^{1}$.

\begin{tabular}{|c|c|c|c|}
\hline \multirow[t]{2}{*}{ Variable } & \multicolumn{2}{|l|}{ Breed } & \multirow[t]{2}{*}{$\operatorname{Pr}>F$} \\
\hline & Meishan & White crossbred & \\
\hline No. of litters & 7 & 5 & \\
\hline Ovulation rate (no.) & $18.6 \pm 0.8$ & $15.4 \pm 0.9$ & 0.0286 \\
\hline Uterine capacity (no.) & $8.0 \pm 0.9$ & $7.2 \pm 1.1$ & 0.5917 \\
\hline Fetal survival (\%) & $43.6 \pm 5.8$ & $46.8 \pm 6.9$ & 0.7311 \\
\hline Fetal weight (g) & $597.9 \pm 33.3$ & $646.5 \pm 41.7$ & 0.3806 \\
\hline Placental weight (g) & $169.2 \pm 8.8$ & $164.11 \pm 11.1$ & 0.7240 \\
\hline Placental wt. variation $(\%)^{2}$ & $29.5 \pm 3.4$ & $37.9 \pm 4.2$ & 0.2315 \\
\hline Placental efficiency ${ }^{3}$ & $3.7 \pm 0.2$ & $4.1 \pm 0.2$ & 0.2610 \\
\hline Allometric growth ${ }^{4}$ & $0.40 \pm 0.06$ & $0.60 \pm 0.07$ & 0.0712 \\
\hline
\end{tabular}

\footnotetext{
1 Values are reported as least-squares means \pm SEM as determined by MIXED model analysis (refer to Methods for specific model details).

2 Based on the litter average weight coefficient of variation.

3 Based on the fetal:placental weight ratio.

4 Allometric growth was assessed by the slope of the linear regression of $\ln$ fetal weight to ln placental weight within individual litters and measures fetal sparing in which a slope of 1 indicates fetal weight is equally correlated with placental weight and is markedly affected by fetal crowding.
} 


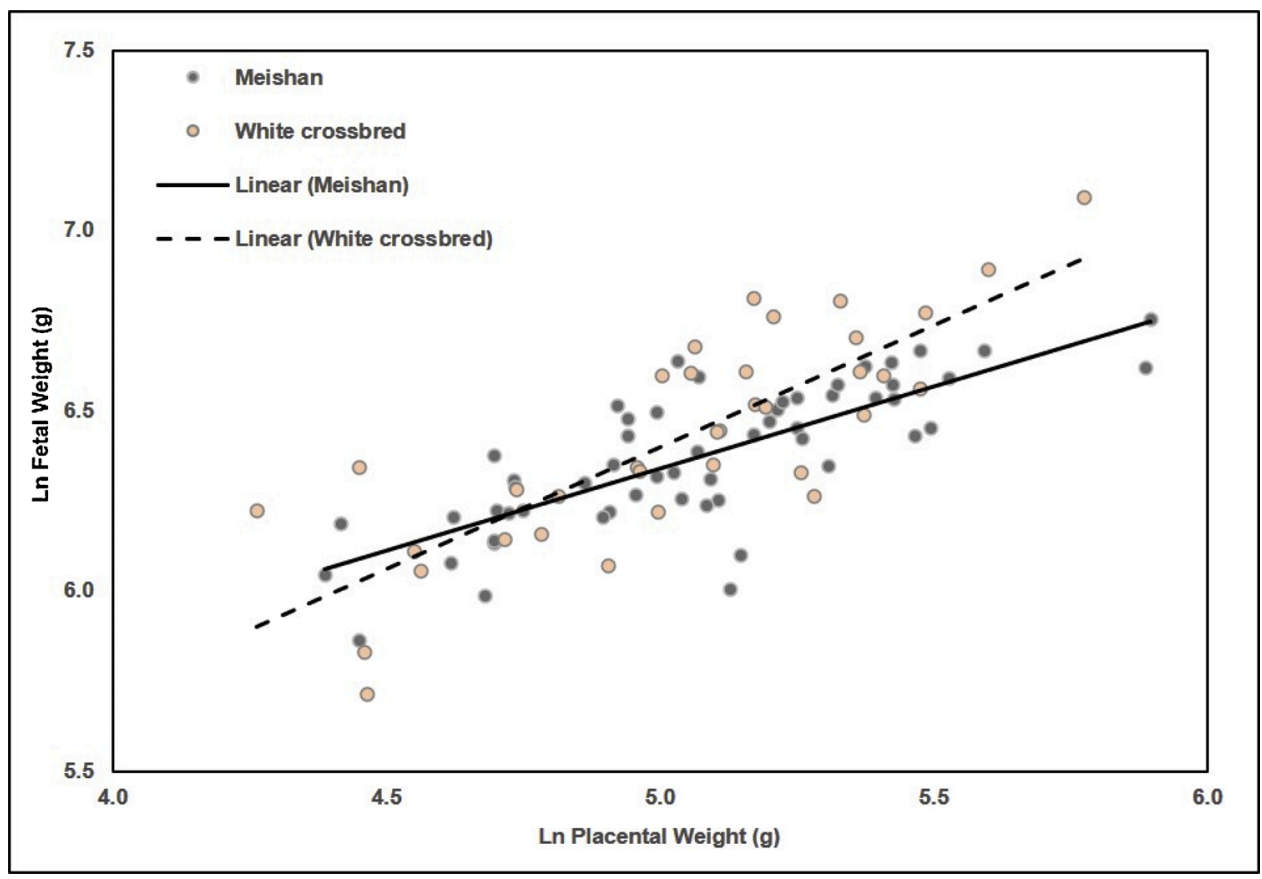

Fig. 3. Scatterplots of the natural log fetal weight to natural log placental at day 100 of gestation when there was intrauterine crowding in Meishan (grey dots) or White crossbred (beige dots) gilts; The linear regression for these relationships (Meishan $=$ solid line; White crossbred $=$ dotted line) indicates there was an allometric growth rate for piglets of each litter (corresponding slopes; Meishan litters $=0.4031 \pm 0.0618 \mathrm{~g}$; White crossbred $=0.6005 \pm 0.0732 \mathrm{~g})$ tended to be less $(P=0.0712)$ for Meishan litters compared to White crossbred; indicating there is a fetal sparing affect for Meishan pregnancies when there is intrauterine crowding.

Table 2

Effect of breed and fetal size on gross placental morphology at day 100 of gestation between Meishan (CM) and White crossbred (WC) gilts when there was intrauterine crowding. ${ }^{1}$.

\begin{tabular}{|c|c|c|c|c|c|}
\hline \multirow[t]{2}{*}{ Variable } & \multicolumn{4}{|c|}{ Breed by Fetal Size } & \multirow[t]{2}{*}{$\operatorname{Pr}>F^{2}$} \\
\hline & CM Small & CM Large & WC Small & WC Large & \\
\hline Fetal weight (g) & $481.1 \pm 54.9$ & $747.1 \pm 54.9$ & $459.1 \pm 65.1$ & $810.0 \pm 65.1$ & $\mathrm{~S}<0.0001$ \\
\hline Placental weight $(g)$ & $126.7 \pm 22.7$ & $221.1 \pm 22.7$ & $109.7 \pm 26.9$ & $214.0 \pm 26.9$ & $S=0.0008$ \\
\hline Placental efficiency ${ }^{3}$ & $4.2 \pm 0.4$ & $3.6 \pm 0.4$ & $4.4 \pm 0.5$ & $3.8 \pm 0.5$ & N.S. \\
\hline Volume displacement (ml) & $118.9 \pm 20.3$ & $201.3 \pm 20.3$ & $97.7 \pm 24.0$ & $200.8 \pm 24.0$ & $S=0.0005$ \\
\hline Surface area $\left(\mathrm{cm}^{2}\right)$ & $1130 \pm 100$ & $1625 \pm 100$ & $985 \pm 119$ & $1539 \pm 119$ & $S=0.0001$ \\
\hline Length $(\mathrm{cm})$ & $47.6 \pm 3.4$ & $66.9 \pm 3.4$ & $39.8 \pm 4.0$ & $59.6 \pm 4.0$ & $\mathrm{~B}=0.0592 ; \mathrm{S}<0.0001$ \\
\hline Width $(\mathrm{cm})$ & $29.2 \pm 1.1^{\mathrm{a}}$ & $29.8 \pm 1.1^{\mathrm{a}}$ & $28.1 \pm 1.4^{\mathrm{a}}$ & $33.8 \pm 1.4^{\mathrm{b}}$ & $\mathrm{I}=0.0581$ \\
\hline Areolae density $\left(\mathrm{cm}^{2}\right)$ & $8.3 \pm 0.3^{\mathrm{a}}$ & $10.2 \pm 0.3^{b}$ & $6.9 \pm 0.3^{c}$ & $7.0 \pm 0.3^{c}$ & $\mathrm{I}=0.0097$ \\
\hline Estimate total areolae (no.) ${ }^{4}$ & $9488 \pm 783^{\mathrm{a}}$ & $16,422 \pm 783^{b}$ & $6890 \pm 928^{c}$ & $10,722 \pm 928^{\mathrm{a}}$ & $\mathrm{I}=0.0855$ \\
\hline
\end{tabular}

\footnotetext{
${ }^{1}$ Values are reported as least-squares means \pm SEM as determined by MIXED model analysis; The model included the fixed effects of breed, fetal size, interaction of fixed effects, the random effect of gilt within breed and the covariate of litter size.

${ }^{2} \mathrm{~B}$ = breed effect; $\mathrm{S}=$ size effect; $\mathrm{I}=$ breed by size interaction; rows with different superscripts were different $(P<0.05)$.

${ }^{3}$ Based on the fetal:placental weight ratio.

${ }^{4}$ Based on the areolae density and corresponding placental surface area.
}

having the least total numbers of areolae (Table 2). Deviations for differences in the areolae density and the estimated total number of areolae between CM small fetuses and WC large fetuses were likely due to differences in placental surface area between these groups. Furthermore, placentas of CM gilts, irrespective of fetal size, had areolae that were consistently more pronounced and distinct compared to placentas of WC gilts as depicted in Fig. 1.

\subsection{Histological placental morphology}

Data for results reported in Table 3 indicate there is an effect of breed (CM compared with WC) and fetal size (smallest compared with largest littermate) for placental histological morphology at day 100 of the gestational period as a result of intrauterine crowding. Total placental width was less $(P=0.0042)$ for $C M$ compared to WC $(402.5 \pm 10.7 \mu \mathrm{m}$ vs. $460.1 \pm 14.4 \mu \mathrm{m}$, respectively) gilts, 
Table 3

Effect of breed and fetal size on histological placental morphology at day 100 of gestation between Meishan (CM) and White crossbred (WC) gilts when there was intrauterine crowding. .

\begin{tabular}{llllll}
\hline Variable & Breed by Fetal Size & & & \\
\cline { 2 - 4 } & CM Small & CM Large & WC Small & WC Large \\
\hline Total placental width $(\mu \mathrm{m})$ & $417.0 \pm 15.1$ & $388.0 \pm 15.1$ & $470.9 \pm 20.3$ & $449.4 \pm 20.3$ \\
Folded bilayer width $(\mu \mathrm{m})$ & $349.5 \pm 13.4$ & $302.1 \pm 13.4$ & $416.2 \pm 15.9$ & $339.4 \pm 15.9$ & $\mathrm{~B}=0.0042$ \\
Stromal width $(\mu \mathrm{m})$ & $59.1 \pm 10.9$ & $78.9 \pm 10.9$ & $54.3 \pm 12.9$ & $109.8 \pm 12.9$ & $\mathrm{~B}=0.0024 ; \mathrm{S}=0.0004$ \\
\hline
\end{tabular}

${ }^{1}$ Values are reported as least-squares means \pm SEM as determined by MIXED model analysis; The model included the fixed effects of breed, fetal size, interaction of fixed effects, the random effect of gilt within breed and the covariate of litter size.

${ }^{2} \mathrm{~B}=$ breed effect; $\mathrm{S}=$ size effect.

irrespective of fetal size. Similarly, folded bilayer width was less $(P=0.0024)$ in placentas of CM compared to WC gilts (325.8 \pm 9.5 $\mu \mathrm{m}$ compared with $377.8 \pm 11.3 \mu \mathrm{m}$, respectively). In addition, there was an effect $(P=0.0004)$ of fetal size on folded bilayer width with placentas of the smallest littermates having a greater folded bilayer width compared to the placentas of the largest littermates (382.9 $\pm 10.3 \mu \mathrm{m}$ compared with $320.8 \mu \mathrm{m}$, respectively for both breeds). The width of the stroma was less $(P=0.0051)$ in the placentas of the smallest compared to the largest littermates ( $56.8 \pm 8.4 \mu \mathrm{m}$ compared with $94.4 \pm 8.4 \mu \mathrm{m}$, respectively), irrespective of maternal breed. Fetal littermate differences for the placental histological morphology of CM and WC gilts, as depicted in Fig. 4, were not different due to fetal size for total placental and folded bilayer widths. The fetal size difference in placental stromal width, however, was less $(P=0.0466)$ in CM $(21.3 \pm 13.8 \mu \mathrm{m})$ compared to WC $(70.9 \pm 16.3 \mu \mathrm{m})$ gilts.

\section{Discussion}

Because of the essential functions of the placenta for exchange of gases, nutrients, and wastes to developing fetuses, the pig placenta has major functions in uterine capacity, fetal growth and viability, which further has effects on postnatal piglet growth and viability. Uterine crowding also has effects on fetal growth and placental development, resulting in lesser fetal weights (Freking et al., 2007) and altered placental size, structure, and function (Vallet and Freking, 2007; Vallet et al., 2014); with this being a mechanism for increased within-litter birth weight variation and smaller piglets that result in increased preweaning piglet mortality. Unique pig breeds can be used for the study of reproductive prolificacy and improved preweaning mortality, particularly the CM pig, which has less preweaning mortality compared to Western breeds even though there are large litters with smaller average piglet weights (Legault, 1985; Lee and Haley, 1995). In the present study, there were breed differences in placental development between CM and WC gilts in response to intrauterine crowding, both on gross and histological levels. These differences may indicate that mechanisms for accommodating intrauterine crowding differ between CM and WC breeds.

In the current study, ovulation rate was greater for similar-aged CM compared to WC gilts when there was UHO to induce intrauterine crowding. The corresponding ovulation rates for CM and WC gilts in the present study were similar to the ovulation rates for intact CM and WC gilts in a previous study (Miles et al., 2012). The results from the first reported use of UHO in CM females indicated with UHO there was compensatory ovarian hypertrophy, resulting in similar ovulation rates as that of intact females but with only one ovary and half of the uterine space; thereby, inducing uterine crowding (Christenson et al., 1987). The breed differences in ovulation in the current study are consistent with results from previous studies with intact females indicating age-matched CM dams have greater ovulation rate compared with Western breed dams (Ashworth et al., 1990; Christenson, 1993; Miles et al., 2012). This difference in ovulation rate is likely due to the younger pubertal age ( $~ 80-100$ days) for CM compared to WC females (Christenson, 1993; Kuehn et al., 2009); thereby, resulting in 3-5 more ovulations at a fixed age for CM females.

Even though there were differences in ovulation rates, there were no breed differences in uterine capacity or fetal survival in the current study following intrauterine crowding. Inconsistencies in litter size and fetal survival have been reported when comparing differences between CM and Western breed females with intact uteri. Results from studies evaluating litter size for purebred CM to purebred Western breeds (i.e., Large White or Yorkshire) of various ages indicate there is a larger litter size for CM compared to purebred females of Western breeds (White et al., 1993; Haley et al., 1995). It, however, has been reported that there are no differences in prenatal survival between Large White and CM females at first and second parities (Haley et al., 1995). In contrast, at the second parity, CM females had a lesser embryo survival at the mid-gestational period ( d day 50) compared to Yorkshire females (White et al., 1993). Furthermore, there were only small differences in litter size and fetal survival in the early gestational period (day 30) between purebred CM and White crossbred intact gilts of the same age (Christenson, 1993). Inconsistencies in litter size and fetal survival between females of CM and Western breeds in various studies may be reflective of differences in reproductive performance between the CM imported to Europe and USA and subsequent management of these divergent CM populations. It has been hypothesized that there is a greater uterine capacity for CM females because of an innate mechanism for greater reproductive prolificacy (Christenson et al., 1993; Ford et al., 2002; Vallet et al., 2002). In all previous studies where there was evaluation of litter size between females of $\mathrm{CM}$ and Western breeds, intact females were evaluated without there being a complete assessment of uterine capacity due to the effects of ovulation rate on litter size, particularly in the young female (Christenson et al., 1987). As a result, to fully assess uterine capacity, it is necessary to have uterine crowding either by induction of superovulation, use of embryo transfer, or surgically using the UHO to effectively evaluate uterine capacity. Results from the current study are not entirely consistent with previous hypotheses that the CM females have greater uterine capacity compared to Western breed contemporaries. Although uterine capacity was not different in the 


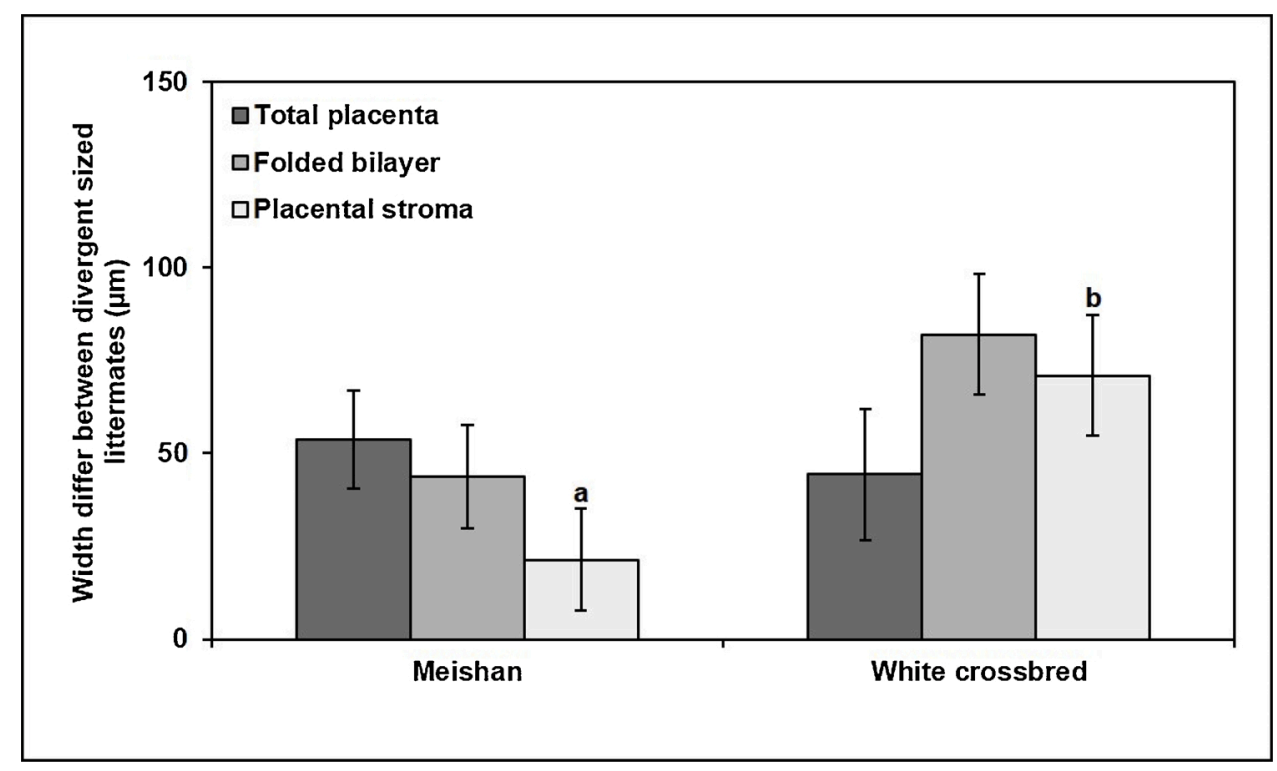

Fig. 4. Differences in total placental (dark grey), folded bilayer (mid grey) and placental stromal (light grey) width in placentas between the divergent-sized littermate fetuses when there was intrauterine crowding in Meishan or White crossed gilts; Values are reported as least-squares means \pm SEM as determined by MIXED model analysis; Columns with different superscripts (placental stroma) were different $(P=0.0466)$ between Meishan compared to White crossbred gilts.

present study, there were some indications the uterine capacity was greater in CM gilts even though there were a limited number of observations. A larger scale evaluation of uterine capacity may be necessary to fully evaluate this hypothesis.

Fetal and placental weights were not different at day 100 of the gestational period for CM or WC gilts. This finding was unexpected and inconsistent with previous findings when there was comparison of fetus, placenta, and corresponding piglet birth weights for intact dams where there were lesser fetal (Finch et al., 2002; Vallet et al., 2003; Ashworth et al., 2013), placental (Bazer et al., 1988; Christenson, 1993), and piglet birth (Le Dividich et al., 1991; White et al., 1993; Miles et al., 2012) weights for CM females compared with those of Western breeds. Intrauterine crowding induced in dams using UHO results in reduced fetal and placental weights when compared to intact dams throughout gestation (Knight et al., 1977). Considering these findings, one plausible explanation for the limited differences in fetal and placental weights of CM and WC gilts in the present study may be a lesser sensitivity to intrauterine crowding on fetal and placental growth for females of the CM breed; thereby, resulting in only slightly lesser fetal and placental weights for CM compared to WC gilts in response to intrauterine crowding following UHO. Intrauterine crowding has a large effect on fetal growth and subsequent within-litter birth weight variation (Foxcroft et al., 2006; Wang et al., 2017). Results from previous studies, however, indicate that CM conceptuses elongate to a lesser extent during early pregnancy, resulting in lesser negative interactions between adjacent conceptuses (Bazer et al., 1988; Ford, 1997). A lesser sensitivity to intrauterine crowding in CM gilts is further supported by the lesser within-litter fetal weight variation for CM compared to WC gilts in the current study. Furthermore, when comparing the allometric growth rate between CM and WC gilts when there was intrauterine crowding, there was a reduction in fetal allometric growth rate for CM compared to WC gilts. Allometric growth is a measurement of the sensitivity of deviations of growth between fetus and placenta (Vallet and Freking, 2007), where a slope (i.e., allometric growth rate) of 1 in this relationship indicates proportional growth and slopes less than 1 are indicative of a fetal sparing effect unaffected by changes in placental growth (Vallet et al., 2013). When considered together, these results indicate fetal and placental development in CM gilts are less sensitive to intrauterine crowding when compared to that of WC gilts. Although the exact mechanisms for limited sensitivity in fetal growth to intrauterine crowding for CM gilts are not clear, one likely mechanism involves the development and function of the placenta.

When evaluating gross morphology of placentas for divergent-sized littermates following intrauterine crowding for CM or WC gilts, volume displacement, surface area, and length of placentas were less in the smallest littermates compared to largest contemporaries, regardless of breed. Interestingly, the placentas of CM gilts, irrespective of fetal size, were longer than those for WC gilts; whereas, the placentas for the largest littermate WC gilts was wider compared to all other groups, indicating there were differences in placental width for WC, but not CM gilts following intrauterine crowding. The greater placental length in CM gilts further supports the thought that there is a lesser sensitivity to intrauterine crowding in CM gilts because placental length decreases when there is intrauterine crowding compared to what occurs in intact control females (Knight et al., 1977). When there are larger numbers of fetuses, there is a greater uterine length particularly during the later gestational period (Wu et al., 1987). Although uterine length was not recorded in the current study, one likely mechanism for a greater length of placentas in CM gilts may be an increased uterine length possibly as a result of an increase in uterine capacity.

In the current study, there was a breed by fetal size interaction for placental areolae density indicating the greater areolae density for CM compared to WC gilts. Although the largest littermate fetuses in CM gilts had greater areolae densities compared to smaller 
littermate contemporaries, the smaller placentas in CM gilts had greater areolae density compared to fetuses of either size in WC gilts. Furthermore, findings from visual evaluation of placental areolae between the breeds, irrespective of fetal size (Fig. 1), indicated placentas of CM gilts had more pronounced and distinct areolae compared to those of WC gilts. Placental areolae form over the uterine glands and have essential functions in uptake of glandular secretions (i.e., histotrophic exchange) into the placenta (Sinowatz and Friess, 1983; Dantzer and Leiser, 1993). Intrauterine crowding, as a result of UHO, results in a reduction in both the density and total number of placental areolae throughout the gestational period compared to non-crowded intact controls (Knight et al., 1977). Although histotrophic exchange is primarily thought to result in a large quantity of nutrient transfer during pre- and peri-implantation stages of gestation (Bazer et al., 2012), results from histological and biochemical analysis of glandular secretions at the maternal gland and placental areolae interface indicate the importance of these glandular secretions throughout gestation, particularly during late gestation when fetal growth is maximal (Friess et al., 1981; Perry and Crombie, 1982). Considering the importance of the placental areolae for the uptake of glandular secretion, the greater density and development of the areolae in CM compared to WC gilts when there was intrauterine crowding in the present study indicates this is a mechanism by which CM gilts have a lesser effect of intrauterine crowding on fetal and placental growth.

Based on histological findings, the maternal-placental interface of the pig placenta consists of a folded bilayer of intact uterine epithelium and trophectoderm embedded in loose placental stroma (Fig. 2; (Leiser and Kaufmann, 1994; Vallet and Freking, 2007)). In the current study, the widths of the total placental interface and folded bilayer were less in placentas of CM than WC gilts, irrespective of fetal size. There was a lesser folded bilayer width for placentas of CM and Yorkshire females during late gestation in a previous study (Hong et al., 2014). Conversely, in this previous study when there was an assessment of fold complexity based on the fold length per unit area of placenta, there was a greater complexity in the folded bilayer for CM compared to Yorkshire gilts indicating this complexity was due to greater abundance of heparanase in placentas of CM gilts resulting in structural modification of the folded bilayer (Hong et al., 2014). Although these results indicate there are compensatory mechanisms within the placentas of CM gilts that result in an enhanced surface area at the maternal-placental interface, it is not clear what the effects of litter and fetal size are because there is no information of fetal nor litter size of the placentas reported (Hong et al., 2014).

The folded bilayer width was also greater for the smallest littermate fetus of gilts of both breeds in the current study. Conversely, placental stroma weight was less for placentas of the smallest littermate fetus, regardless of breed. Vallet and Freking previously reported that the smallest fetal littermates have folds of bilayers that are wider, however, have a lesser placental stromal depth compared to the larger contemporaries when there is intrauterine crowding in gilts (Vallet and Freking, 2007). It was hypothesized that differences in placental histology among divergent-sized littermates when there was intrauterine crowding resulted in a compensatory response due to less uterine surface access for the smallest littermates for developing a larger maternal-fetal interface by increasing the surface area; thereby, resulting in a deeper folded bilayer which resulted in a smaller placental stroma. At a certain point during placental development the placental stroma tissue becomes limited and thus this limits growth and development of smaller littermates resulting in greater susceptibility for pre- and post-natal mortality (Vallet and Freking, 2007). Although the findings from the current study support the compensatory hypothesis that small littermates have a greater folded bilayer width and reduced stromal width, regardless of breed, the breed difference in divergent-sized littermates for placental stromal width was less for CM compared with WC gilts (Fig. 4). The placentas of CM gilts, therefore, may be less sensitive to limitations in placental stroma development among divergent-sized littermates, or alternatively there may be mechanisms for improved maintenance of placental stroma among littermates.

\section{Conclusions}

In conclusion, the results from the present study indicate there is altered placental development for both histotrophic and hemotrophic exchange components of placenta for CM compared to WC gilts when there is intrauterine crowding. Placentas of CM gilts had a greater density with morphologically different placental areolae compared to those of WC gilts; thereby, increasing the potential for greater uptake of secretions from uterine glands of CM gilts. In contrast, CM gilts had lesser differences among divergent-sized littermates in hemotrophic exchange area (i.e., placental stroma width) compared to WC gilts indicating greater structural uniformity of placental development. These alterations in placental development in CM gilts provide potential mechanisms for a lesser sensitivity to fetal growth effects, decreased within-litter fetal weight variation and less allometric growth when there is intrauterine crowding.

\section{CRediT authorship contribution statement}

Jeremy R. Miles: Conceptualization, Data curation, Formal analysis, Methodology, Writing - original draft. Jeffrey L. Vallet: Conceptualization, Methodology, Writing - review \& editing.

\section{Declaration of Competing Interest}

The authors report no declarations of interest.

\section{Acknowledgements}

The authors would like to acknowledge Mr. David Sypherd and Dr. Elane Wright-Johnson for technical support with UHO surgeries 
and data collection, Drs. Gary Rohrer and Clay Lents for critical review of the manuscript, Mrs. Amber Moody for secretarial assistance, and the USMARC swine crew for animal husbandry.

\section{References}

Ashworth, C.J., Haley, C.S., Aitken, R.P., Wilmut, I., 1990. Embryo survival and conceptus growth after reciprocal embryo transfer between Chinese Meishan and Landrace x Large White gilts. J. Reprod. Fertil. 90, 595-603.

Ashworth, C.J., Nwagwu, M.O., McArdle, H.J., 2013. Genotype and fetal size affect maternal-fetal amino acid status and fetal endocrinology in Large White x Landrace and Meishan pigs. Reprod. Fertil. Dev. 25, 439-445.

Bazer, F.W., Thatcher, W.W., Martinat-Botte, F., Terqui, M., 1988. Conceptus development inlarge white and prolific Chinese Meishan pigs. J. Reprod. Fertil. 84, $37-42$.

Bazer, F.W., Song, G., Kim, J., Dunlap, K.A., Satterfield, M.C., Johnson, G.A., Burghardt, R.C., Wu, G., 2012. Uterine biology in pigs and sheep. J. Anim. Sci. Biotechnol. 3, 23.

Biensen, N.J., Wilson, M.E., Ford, S.P., 1998. The impact of either a Meishan or Yorkshire uterus on Meishan or Yorkshire fetal and placental development to days 70, 90, and 110 of gestation. J. Anim. Sci. 76, 2169-2176.

Christenson, R.K., 1993. Ovulation rate and embryonic survival in Chinese Meishan and white crossbred pigs. J. Anim. Sci. 71, $3060-3066$.

Christenson, R.K., Leymaster, K.A., Young, L.D., 1987. Justification of unilateral hysterectomy-ovariectomy as a model to evaluate uterine capacity in swine. J. Anim. Sci. $65,738-744$.

Christenson, R.K., Vallet, J.L., Leymaster, K.A., Young, L.D., 1993. Uterine function in Meishan pigs. J. Reprod. Fertil. Suppl. 48, 279-289.

Dantzer, V., Leiser, R., 1993. Microvasculature of regular and irregular areolae of the areola-gland subunit of the porcine placenta: structural and functional aspects. Anat. Embryol. 188, 257-267.

FASS, 2010. Guide for the Care and Use of Agricultural Animals in Research and Teaching. Federation of Animal Science Societies Champaign, IL.

Finch, A.M., Antipatis, C., Pickard, A.R., Ashworth, C.J., 2002. Patterns of fetal growth within Large White x Landrace and Chinese Meishan gilt litters at three stages of gestation. Reprod. Fertil. Dev. 14, 419-425.

Ford, S.P., 1997. Embryonic and fetal development in different genotypes in pigs. J. Reprod. Fertil. Suppl. 52, 165-176.

Ford, S.P., Vonnahme, K.A., Wilson, M.E., 2002. Uterine capacity in the pig reflects a combination of uterine environment and conceptus genotype effects. J. Anim. Sci. 80 (E. Suppl. 1), E66-E73.

Foxcroft, G.R., Dixon, W.T., Novak, S., Putman, C.T., Town, S.C., Vinsky, M.D., 2006. The biological basis for prenatal programming of postnatal performance in pigs. J. Anim. Sci. 84 (Suppl), E105-112.

Freking, B.A., Leymaster, K.A., Vallet, J.L., Christenson, R.K., 2007. Number of fetuses and conceptus growth throughout gestation in lines of pigs selected for ovulation rate or uterine capacity. J. Anim. Sci. 85, 2093-2103.

Friess, A.E., Sinowatz, F., Skolek-Winnisch, R., Traautner, W., 1980. The placenta of the pig. I. Fine structural changes of the placental barrier during pregnancy. Anat. Embryol. 158, 179-191.

Friess, A.E., Sinowatz, F., Skolek-Winnisch, R., Trautner, W., 1981. The placenta of the pig. II. The ultrastructure of the areolae. Anat. Embryol. 163 , 43-53.

Haley, C.S., Lee, G.J., 1993. Genetic basis of prolificacy in Meishan pigs. J. Reprod. Fertil. Suppl. 48, $247-259$.

Haley, C.S., Lee, G.J., Ritchie, M., 1995. Comparative reproductive performance in Meishan and Large White pigs and their crosses. Anim. Sci. 60, $259-267$.

Herpin, P., Le Dividich, J., Amaral, N., 1993. Effect of selection for lean tissue growth on body composition and physiological state of the pig at birth. J. Anim. Sci. 71, 2645-2653.

Hong, L., Hou, C., Li, X., Li, C., Zhao, S., Yu, M., 2014. Expression of heparanase is associated with breed-specific morphological characters of placental folded bilayer between Yorkshire and Meishan pigs. Biol. Reprod. 90, 56.

Knight, J.W., Bazer, F.W., Thatcher, W.W., Franke, D.E., Wallace, H.D., 1977. Conceptus development in intact and unilaterally hysterectomized-ovariectomized gilts: interrelations among hormonal status, placental development, fetal fluids and fetal growth. J. Anim. Sci. 44, 620-637.

Kuehn, L.A., Nonneman, D.J., Klindt, J.M., Wise, T.H., 2009. Genetic relationships of bodycomposition, serum leptin, and age at puberty in gilts. J. Anim. Sci. 87, 477-483.

Le Dividich, J., Mormede, P., Catheline, M., Caritez, J.C., 1991. Body composition and cold resistance of the neonatal pig from European (Large White) and Chinese (Meishan) breeds. Biol. Neonate 59, 268-277.

Lee, G., Haley, C., 1995. Comparative farrowing to weaning performance in meishan and large white pigs and their crosses. Anim. Sci. 60, $269-280$.

Legault, C., 1985. Selection of breeds, strains and individual pigs for prolificacy. J. Reprod. Fertil. Suppl. 33, 151-166.

Leiser, R., Kaufmann, P., 1994. Placental structure: in a comparative aspect. Exp. Clin. Endocrinol. 102, $122-134$.

Mesa, H., Safranski, T.J., Cammack, K.M., Weaber, R.L., Lamberson, W.R., 2006. Genetic and phenotypic relationships of farrowing and weaning survival to birth and placental weights in pigs. J. Anim. Sci. 84, 32-40.

Miles, J.R., Vallet, J.L., Ford, J.J., Freking, B.A., Cushman, R.A., Oliver, W.T., Rempel, L.A., 2012. Contributions of the maternal uterine environment and piglet genotype on weaning survivability potential: I. Development of neonatal piglets after reciprocal embryo transfers between Meishan and White crossbred gilts. J. Anim. Sci. 90, 2181-2192.

Perry, J.S., Crombie, P.R., 1982. Ultrastructure of the uterine glands of the pig. J. Anat. 134, 339-350.

Roberts, R.M., Raub, T.J., Bazer, F.W., 1986. Role of uteroferrin in transplacental iron transport in the pig. Fed. Proc. 45, $2513-2518$.

Roehe, R., Kalm, E., 2000. Estimation of genetic and environmental risk factors associated with pre-weaning mortality in piglets using generalized linear mixed models. Anim. Sci. 70, 227-240.

SAS, 2003. The SAS System for Windows, Release 9.1, SAS. Statistical Analysis System Institute, Inc., Cary, NC.

Sinowatz, F., Friess, A.E., 1983. Uterine glands of the pig during pregnancy. An ultrastructural and cytochemical study. Anat. Embryol. 166, 121-134.

Steel, R.G.D., Torrie, J.H., Dickey, D.A., 1997. Principles and Procedures of Statistics: A Biometrical Approach. McGraw-Hill Inc., New York.

Vallet, J.L., Freking, B.A., 2007. Differences in placental structure during gestation associated with large and small pig fetuses. J. Anim. Sci. 85, $3267-3275$.

Vallet, J.L., Leymaster, K.A., Christenson, R.K., 2002. The influence of uterine function on embryonic and fetal survival. J. Anim. Sci. 80, E115-E125.

Vallet, J.L., Klemcke, H.G., Christenson, R.K., Pearson, P.L., 2003. The effect of breed and intrauterine crowding on fetal erythropoiesis on day 35 of gestation in swine. J. Anim. Sci. 81, 2352-2356.

Vallet, J.L., McNeel, A.K., Johnson, G., Bazer, F.W., 2013. Triennial Reproduction Symposium: limitations in uterine and conceptus physiology that lead to fetal losses. J. Anim. Sci. 91, 3030-3040.

Vallet, J.L., McNeel, A.K., Miles, J.R., Freking, B.A., 2014. Placental accommodations for transport and metabolism during intra-uterine crowding in pigs. J. Anim. Sci. Biotechnol. 5, 55.

Wang, J., Feng, C., Liu, T., Shi, M., Wu, G., Bazer, F.W., 2017. Physiological alterations associated with intrauterine growth restriction in fetal pigs: causes and insights for nutritional optimization. Mol. Reprod. Dev. 84, 897-904.

White, B.R., McLaren, D.G., Dziuk, P.J., Wheeler, M.B., 1993. Age at puberty, ovulation rate, uterine length, prenatal survival and litter size in Chinese Meishan and Yorkshire females. Theriogenlogy 40, 85-97.

Wilson, M.E., Ford, S.P., 2001. Comparative aspects of placental efficiency. Reprod. Suppl. 58, $223-232$.

Wilson, M.E., Biensen, N.J., Youngs, C.R., Ford, S.P., 1998. Development of Meishan and Yorkshire littermate conceptuses in either a Meishan or Yorkshire uterine environment to day 90 of gestation and to term. Biol. Reprod. 58, 905-910.

Wu, M.C., Hentzel, M.D., Dziuk, P.J., 1987. Relationships between uterine length and number of fetuses and prenatal mortality in pigs. J. Anim. Sci. 65, 762-770. 